\title{
Outcome of diaphragmatic herniation and eventration repair in adults
}

\author{
Khakural P, Sapkota R, Sayami P \\ Department of Cardiothoracic and Vascular Surgery, Manmohan Cardiothoracic Vascular and Transplant Center, \\ Kathmandu, Nepal.
}

Correspondence: Prabhat Khakural,

Email: pkhakural@gmail.com

\begin{tabular}{l} 
Abstract \\
\hline \hline Introduction: Diaphragmatic hernia and eventration are amongst the less commonly encountered \\
thoracic surgical problems in Nepal. Unlike, the cases of traumatic herniation, adults with congenital \\
herniation and eventration seek medical attention very late. \\
Methods: It is a retrospective observational study of patients presenting with diaphragmatic \\
herniation and eventration at Manmohan Cardiothoracic Vascular and Transplant Center, Kathmandu, \\
Nepal. Medical records of five years (May, 2010 to April, 2015) were reviewed. Analysis of the \\
demographic profile, clinical features, management and outcome was done. \\
Results: There were a total of 15 patients who were diagnosed to have diaphragmatic herniation \\
and eventration. There were eight cases of herniation and seven cases of eventration. There were \\
three cases of acute diaphragmatic herniation. Thoracic trauma was found to be associated in three \\
cases of herniation only. The mean age at presentation was 46.5 years. Thoracic trauma was seen in \\
younger age (mean age being 34 yrs). There were two cases of morgagni hernia and one of these was \\
diagnosed incidentally. Mean duration of symptoms was two months. The most common presenting \\
symptoms were shortness of breath and cough. Twelve cases were repaired via thoracotomy. Mean \\
size of diaphragmatic defect was six centimeters. The most commonly herniated organ was stomach \\
followed by omentum. Plication was the most commonly performed procedure in eventration and \\
primary repair was done in six cases of herniation and mesh repair in two cases. Only two patients \\
had superficial surgical site infection. Mean duration of hospital stay was eight days. The patients \\
were doing good upto mean follow up period of four months. \\
Conclusion: Diaphragmatic herniation and eventration in symptomatic patients should be managed \\
surgically. Surgical approaches can be thoracotomy, laparotomy and Video Assisted Thoracoscopic \\
Surgery. Outcome following surgery is good with minimal postoperative complications. \\
Keywords: diaphragmatic hernia; eventration; morgagni hernia \\
\hline \hline
\end{tabular}

\section{Introduction}

Diaphragmatic herniation and eventration are rare congenital anomalies involving the abnormal development of the diaphragm. The estimated rate of occurrence of congenital diaphragmatic hernia varies from 1:2000 to 1:4000 live births. ${ }^{1}$ Diaphragmatic herniation have well recognized defects in the diaphragm through which abdominal contents herniate to thoracic cavity, whereas eventration of diaphragm is abnormally elevated portion of diaphragm (one or both) from muscular atrophy or paralysis. ${ }^{2}$ Diaphragmatic herniation and eventration can also be acquired later in life. The congenital forms tend to present early in life. However the congenital forms are very rare in adults. The acquired forms in adults are mostly related to trauma. The incidence of diaphragmatic injury is $7 \%$ in those suffering blunt abdominal and/or thoracic trauma and $3 \%$ to $15 \%$ in those with penetrating 
injury. ${ }^{3}$ In our part of the world, adult patients of congenital diaphragmatic herniation and eventration, usually tend to ignore the milder respiratory symptoms and abdominal discomfort and hence seek medical attention very late. However those with acute trauma are brought to medical facilities early. Similarly there is another subset of asymptomatic patients in whom the diagnosis is incidental. Majority of the patients with diaphragmatic herniation and eventration have shortness of breath, recurrent respiratory tract infection and gastrointestinal symptoms. However, the possibility of bowel incarceration and strangulation, severe pulmonary disease and intra abdominal organ dysfunction warrants repair even in asymptomatic patients. The diagnosis is made with the imaging modalities like X-rays and Computed Tomography (CT) scans. ${ }^{4}$ The treatment is always surgical and includes replacing the hernial content in the abdomen and closing the diaphragmatic defect. Different surgical approaches are available. In cases of acute trauma, laparotomy seems plausible and in other forms, thoracotomy or Video Assisted Thoracoscopic Surgery (VATS) repair can be safely done with a favorable outcome. ${ }^{5,6}$ There have been reports of laparoscopic hernia repair as well. ${ }^{7}$ Repair can be done primarily in small defects whereas in as many as $53 \%$ of cases, primary closure is impossible because of the size of the defect; hence mesh repair or autologous flap is necessary. ${ }^{8}$ In cases of eventration plication of the diaphragm can be done either by thoracotomy or VATS.

\section{Methods}

This hospital based retrospective observational study was conducted at Manmohan Cardiothoracic Vascular and Transplant Center, Kathmandu, over a period of five years from May, 2010 to April, 2015. All the patients presenting with diaphragmatic herniation and eventration were studied. All patients underwent CT scan of abdomen and chest prior to surgery and the repair was by thoracotomy, laparotomy or VATS according to the operating surgeon's preference. The hospital protocol was plication or mesh repair based on the strength and adequacy of the diaphragmatic tissue. Three parallel rows of prolene stich were used to plicate the diaphragm and a prolene mesh was used for mesh repair.

Medical records were reviewed with an objective of studying the clinical profile of patients with diaphragmatic herniation and eventration, different approaches of treatment and the outcome of surgery in these patients. Descriptive analysis was conducted using the SPSS 17 software. Qualitative variables were expressed as percentages and quantitative variables as means.

\section{Results}

Fifteen patients of diaphragmatic herniation (eight patients) and eventration (seven patients) were operated during the study period. Amongst these, eight (53.3\%) patients were males and seven (46.6\%) were females. Their age varied from 25 years to 67 years with an average of 46.5 years (Table 1 ).

\section{Table 1: Age distribution}

$\begin{array}{ll}\text { Age (years) } & \mathbf{N}(\%) \\ 20-30 & 2(13.3) \\ 31-40 & 4(26.6) \\ 41-50 & 4(26.6) \\ 51-60 & 4(26.6) \\ 61-70 & 1(6.6)\end{array}$

Most patients, $12(80 \%)$ had congenital herniation and eventration, while three $(20 \%)$ patients had acquired traumatic diaphragmatic herniation (Table 2).

\section{Table 2: Causes of herniation}

$\begin{array}{ll}\text { Cause } & \text { N }(\%) \\ \text { Traumatic hernia } & 3(20) \\ \text { Congenital hernia } & 5(33.3) \\ \text { Congenital eventration } & 7(46.6)\end{array}$

Most of these patients, $13(86.6 \%)$ patients had a left sided pathology whereas one patient had right sided morgagni hernia and the other one had a right sided eventration. Out of five congenital herniation, two $(13.3 \%)$ patients had Morgagni hernia and three (20\%) had Bochdalek Hernia. Duration of symptoms ranged from three days to one year with an average of two months. Most common presenting symptoms included shortness of breath in seven (46.6\%) patients followed by cough in five (33.3\%) patients (Table 3).

\section{Table 3: Presenting complaints}

$\begin{array}{ll}\text { Symptoms } & \text { N }(\%) \\ \text { Shortness of breath } & 7(46.6) \\ \text { Cough } & 5(33.3) \\ \text { Epigastric pain } & 3(20) \\ \text { Chest pain } & 2(13.3)\end{array}$


All patients had undergone preoperative Computed Tomography Scan. Most patients, 12(80\%) underwent repair via thoracotomy, two $(13.3 \%)$ patients via laparotomy and one $(6.6 \%)$ via VATS. All the cases of diaphragmatic eventration were repaired by plication with three parallel rows of prolene stitch. Primary repair of the hernia was done in six $(40 \%)$ patients and mesh repair was done in two $(13.3 \%)$ patients. The average size of diaphragmatic defect was six centimeters. Stomach was the most commonly herniated organ in four (26.6\%) patients (Table 4).

\section{Table 4: Hernial contents}

$\begin{array}{ll}\text { Hernial content } & \text { N }(\%) \\ \text { Stomach } & 4(26.6) \\ \text { Omentum } & 3(20) \\ \text { Small bowel } & 2(13.3) \\ \text { Large bowel } & 1(13.3) \\ \text { Spleen } & 1(13.3)\end{array}$

The duration of surgery ranged from 75 minutes to 120 minutes with an average of 100 minutes. The average duration of Intensive Care Unit stay was two days (ranging from one day to four days). The average drain volume was 300 milliliters and drains were taken out in second postoperative day in all the patients. Thoracic epidural catheter was placed in $10(66.6 \%)$ patients and extra pleural catheter was placed in two $(13.3 \%)$ patients for postoperative analgesia. There was not any major complication in any of the patients. Only two patients had superficial surgical site infection. The duration of hospital stay ranged from five days to twelve days, with an average of eight days. All the patients were doing well over a mean follow up period of four months.

\section{Discussion}

Congenital Diaphragmatic Hernia was first described by Lazarus Riverius in 1690, in a post-mortem study in a 24 year old man. ${ }^{9}$ It was in 1769, when Giovanni Morgagni first described Morgagni hernia and in 1848, Vincent Alexander Bochdalek described the Bochdalek Hernia. ${ }^{2}$ Moragagni hernia is characterized by herniation through the foramina of Morgagni, located adjacent to xiphoid process. Most of these occur on the right side and are generally asymptomatic except in new-born where they may present with respiratory distress. Bochdalek hernia, the commonest type of congenital diaphragmatic hernia, is characterized by herniation through the posterolateral foramen of Bochdalek. Most of these are associated with lung anomalies and they tend to present early in life. ${ }^{10}$ Bochdalek hernia is more common on the left side ( $85 \%$ ), presenting with herniation of mostly bowel and omentum. Liver tend to herniate in cases of right sided Bochdalek hernia (13\%). A "dual hit" hypothesis is postulated for development of congenital diaphragmatic hernia ; the first hit being the defect arising in the embryologic period and second being the impairment of lung development , during further gestation. ${ }^{11}$

Our study revealed that males are more prone to have delayed presentation of the congenital diaphragmatic hernia. Similar results have been shown in other studies. In a study by Gedik et $\mathrm{al}^{2}, 14$ males and six females were found to have congenital diaphragmatic hernia .The mean age at presentation in our study was 46.5 years whereas in the study by Gedik et $\mathrm{al}^{2}$, the mean age at presentation in patients with Morgagni hernia was 59.5 years and in those with Bochdalek hernia was 36.5 years. The commonest symptom is found to be shortness of breath in almost all studies which is a finding similar to ours. However the symptoms can be vague and nonspecific, including chest pains, dyspnoea, and gastrointestinal complaints ${ }^{12}$ Omentum is the most common content in the hernial sac ${ }^{2}$ but we found stomach and omentum are most common content in the hernial sac. The diagnosis can be achieved through a chest X-ray, CT scan, Magnetic Resonance Imaging or an upper gastrointestinal series. ${ }^{13}$ Chest $\mathrm{X}$ ray and CT chest was done in all of our cases to diagnose the condition. The aim of repair is to return the content to the abdomen and repair the diaphragmatic rent by either thoracic or abdominal approach. This can be achieved either by the traditional open technique or minimally invasive approach. ${ }^{14}$ In case of acute traumatic diaphragmatic injury abdominal approach is preferred over the thoracic approach whereas in cases of long standing diaphragmatic herniation thoracic approach is the choice. Most of our patients underwent repair via thoracotomy and two patients underwent repair via laparotomy and in one patient VATS repair was done. However laparoscopic repair was not done in any of the patients. Regarding the repair technique, there is still a debate whether primary closure or mesh repair produce the best results. ${ }^{15}$ However larger defects need mesh repair. ${ }^{8}$ We repaired most of the defects primarily and used mesh when the defect was considerably of large size. In cases of eventration plication was done via thoracotomy. Irrespective of the surgical approach and the repair technique, all of our patients had a good outcome with short ICU and hospital stay without any major complications. 


\section{Conclusion}

Congenital diaphragmatic hernia and eventration in adults are rare. Acute diaphragmatic hernias in adults are mostly related to trauma. Once the diagnosis is made, surgical treatment is imperative in both the types. There are various approaches to the repair like minimally invasive and open surgery. Despite different approaches and techniques, the outcome of surgery is favorable without significant complication.

\section{References}

1. Zhou Y, Du H, Che G.Giant congenital diaphragmatic hernia in an adult.J Cardiothorac Surg.2014; 9:31

2. Gedik E, Tuncer MC, Onat S, AvcI A, TacyIldIz I, Bac B. A review of Morgagni and Bochdalek hernias in adults. Folia Morphol 2011; 70(1):5-12

3. Rosati C. Acute traumatic injury of the diaphragm. Chest Surg Clin North Am. 1998; 8:371-79

4. Eren S, Iris FC. Diaphragmatic hernia: diagnostic approaches with review of the literature. Eur J Rad 2005; 54:448-59

5. Giannoulis K, Sutton R. Bochdalek hernia presenting in adult life:report of an unusual case and review of the literature. Ann Gastroenterol 2004; 17(1):109-12

6. Willemse P, Schutte PR, Plaisier PW. Thoracoscopic repair of a Bochdalek hernia in an adult. Surg Endos $2003 ; 17: 162$

7. Al-Emadi M, Helmy I, Nada MA, Al-Jaber H. Laparoscopic repair of Bochdalek hernia in an adult. Surgical Laparoscopy, Endoscopy and Percutaneous Techniques 1999; 9:423-5

8. Ninos A, Felekouras E, Douridas G, Ajazi E, Manataki A, Pierrakakis S, et al. Congenital diaphragmatic hernia complicated by tension gastrothorax during gastroscopy: report of a case. Surgery Today 2005; $35: 149-52$

9. Anantharamakrishnan R, Senthil KK, Karunanithi R. Congenital Diaphragmatic Hernia (Bochdalek Hernia) in an Adult. Chettinad Health City Medical Journal. (Internet) [Last accessed on 14 January 2015]. Available from www.chcmj.ac.in/journal/pdf/voll no2/congenitaldiaphragmatic.pdf
10. Naunheim KS. Adult presentation of unusual diaphragmatic hernias. Chest Surg Clin N Am 1998; 8: 359-69

11. Mallikarjunappa B, Ashish SR. Congenital Diaphragmatic Hernia: A Case Report. JIMSA 2012; 25(4):247

12. Kocakusak A, Arikan S, Senturk O, Yucel AF. Bochdalek's hernia in an adult with colon necrosis. Hernia 2005; 9: $284-87$

13. Vega MT, Maldonado RH, Vega GT, Vega AT, Liévano EA, Velázquez PM. Late onset congenital diaphragmatic hernia:a case report . Int J Surg Case Rep 2013; 4(11):952-4

14. Esmer D, Alvarez-Tostado J, Alfaro A, Carmona $\mathrm{R}$, Salas M. Thoracoscopic and laparoscopic repair of complicated Bochdalek hernia in adult. Hernia 2008;12: 307-9

15. Contini S, Dalla Valle R, Bonati L, Zinicola R. Laparoscopic repair of a Morgagni hernia: report of a case and review of the literature. J Laparoendosc Adv Surg Tech 1999; 9: 93-9 